Journal of Applied Pharmaceutical Science Vol. 6 (04), pp. 202-205, April, 2016

Available online at http://www.japsonline.com

DOI: 10.7324/JAPS.2016.60429

ISSN 2231-3354 (cc) BY-NC-SA

\title{
Hepatoprotective properties of Dandelion: recent update
}

\author{
Ezhilarasan Devaraj \\ Department of Pharmacology, Saveetha Dental College and Hospitals Saveetha University, Chennai- 600 077, Tamil Nadu, India.
}

\begin{tabular}{l} 
ARTICLE INFO \\
\hline Article history: \\
Received on: $24 / 10 / 2015$ \\
Revised on: $20 / 12 / 2015$ \\
Accepted on: 10/02/2016 \\
Available online: $30 / 04 / 2016$ \\
\hline Key words: \\
Taraxacum officinale, \\
oxidative stress, antioxidant, \\
hepatoprotective
\end{tabular}

\begin{abstract}
Taraxacum officinalis (Dandelion) have been used as folk medicines in China, India, and Russia for the treatment of chronic liver diseases. This review focuses exclusively on published literature pertaining to the potential use of Taraxacum officinalis or Dandelion for the treatment of various chronic liver diseases. Dandelion has been tested against various drugs and chemical induced chronic liver diseases in experimental animals and came out with promising results. In vitro studies also confirm the hepatoprotective, antioxidant and anti-inflammatory properties of dandelion. The extensive literature survey reveal the fact that Taraxacum officinalis or dandelion to be safe and the available evidence on the mechanisms of action appears promising, there are currently insufficient data from well-conducted clinical trials to recommend it use in patients with alcoholic liver chronic liver disease.
\end{abstract}

\section{INTRODUCTION}

The liver is one of the vital organs of human body, being involved in myriad vital functions and regulation of physiological processes. Due to its unique anatomic location and function, liver is vulnerable to many forms of injury. Fortunately, it also has remarkable capacity to repair itself following many types of injuries that it encounters in compensation for the important, yet hazardous functions it undertakes. However, liver disorders following chronic liver injury lead to various pathological changes such as fatty liver, increase in ROS or oxidative stress, necrosis of liver cells, hepatitis, steatosis, cholestasis, vascular lesions, and granuloma and veno-occlusive diseases, increase in the level of inflammatory markers, fibrosis, cirrhosis, hepatocellular carcinoma which further produce portal hypertension and organ failure (Singh et al., 2011).

The conventional treatments of chronic liver injuries such as fibrosis, cirrhosis, steatosis and chronic hepatitis are frequently inadequate due to side effects caused by various drugs and chemicals. To overcome this problem, current research focused on drugs derived from medicinal plants, due to their richness in flavonoid and ployphenolic compounds have been extensively studied against various drug and chemical induced

\footnotetext{
* Corresponding Author

Email: ezhild@gmail.com
}

hepatotoxicity in vivo and in vitro and it is need of the hour (Pereira et al., 2015). There are several plant derived agents have shown promising hepatoprotective properties i.e., dandelion, silymarin, silibinin, curcumin, berberin, resveratrol (Ezhilarasan et al., 2014; Ezhilarasan et al., 2012). Among these dandelion is one of the promising agent obtained from the medicinal plant Taraxacum officinalis. Hence, the present review aimed to gain insight into the recent update on the hepatoprotective properties of Taraxacum officinalis.

\section{Description}

The genus Taraxacum Wiggers, family Asteraceae, subfamily Cichorioideae, tribe Lactuceae, commonly known as dandelion, includes approximately 30-57 varieties with many microspecies, divided into nine sections (Vašut et al., 2015). Dandelion (Taraxacum officinalis), a traditional herbal medicine is used for treatment of jaundice and disorders of the liver, gallbladder and other various hepatic ailments (You et al., 2010; Ahmed et al., 2013,). The folk medicines of China, India, and Russia have recognized dandelion's effect as a liver tonic. Traditional Chinese medicine combines dandelion with other herbs to treat hepatitis (Modaresi, 2012). Conventionally, root and herb from Taraxacum officinale (TO) have been reported to use for the treatment of various ailments, including liver and gallbladder disorders (Gulfraz et al., 2014). 


\section{Phytochemical constituents}

The phytochemical investigation showed that TO has an abundance of terpenoid and sterol (principally taraxacin and taraxacerin), equally distributed in the roots, leaves, and flowers. Other terpene/sterol compounds include beta-amyrin, taraxasterol, and taraxerol, as well as free sterols (sitosterin, stigmasterin, and phytosterin) structurally related to bile (Koo et al., 2004; Schütz et al., 2006). Presence of these biologically active principles in the TO extract have been attributed for its beneficial effects. The terms Taraxacum officinale and dandelion are generally interchangeably used in the literature.

\section{SPECTRUM OF HEPATOPROTECTIVE EFFECTS}

\section{Antioxidant effect}

Oxidative stress is a common feature observed in a wide spectrum of chronic liver diseases including viral hepatitis, alcoholic, and nonalcoholic steatohepatitis (Jiang and Török, 2015). Oxidative stress leads to deleterious processes in the liver and produces liver diseases. Therefore, restoring antioxidants is essential to maintain homeostasis. One method of restoring antioxidants is suggested to consume natural compounds with antioxidant capacity (Casas-Grajales and Muriel, 2015). Dandelion, a natural antioxidant compound has been empirically used due to its health-promoting properties as an anticarcinogenic, anti-inflammatory and anti-oxidant (You et al., 2010). Ethanolic TO leaves and root extract significantly attenuated marker enzymes of liver toxicity (AST and ALT), lipid peroxidation and oxidative stress induced by acetaminophen in mice. The TO extract shown to possess the free radical quenching activities. This protective effects of TO have been suggested to the presence of phenolic compounds in the extract (Colle et al., 2012). In a recent study, ethanolic and n-hexane TO leaves extract significantly decreased the liver marker enzymes, superoxide dismutase (SOD), catalase, lipid peroxidation and glutathione peroxidase $(\mathrm{GPx})$ in rats intoxicated with $\mathrm{CCl}_{4}$. The efficacy of TO ethanolic leaves extract found to be more effective as it compared with n-hexane extract and silymarin against $\mathrm{CCl}_{4}$ induced hepatotoxicity and oxidative stress in rats (Gulfraz et al., 2014).

In $\mathrm{CCl}_{4}$ induced oxidative stress model $\mathrm{TO}$ extract reversed the glutathione (GSH) depletion, up-regulation of Nuclear factor-kB (NF-kB) and increased expression of regulatory inflammatory mediators, such as inducible nitric oxide synthase (iNOS), cyclooxygenase (COX)-2, Tumor necrosis factor- $\alpha$ (TNF- $\alpha$ ) and interleukin (IL)- $1 \alpha$ (Park et al., 2010). These results suggest that TO have a hepatoprotective effect by modulating inflammatory responses and ameliorating oxidative stress. Alcohol is a leading cause of liver disease and is associated with significant morbidity and mortality. Alcohol induced liver diseases represents a spectrum of liver pathology ranging from fatty change to fibrosis to cirrhosis (Dugum and McCullough, 2015). In vitro the protective effects of TO root against alcoholic liver damage were investigated in HepG2/2E1 cells. In this study, ROS was generated by the administration of ethanol in vitro this was consequent to decrease in cell viability by less than $40 \%$. However, cells were simultaneously treated with ethanol and TO hot water root extract did not induce cytotoxicity as compare to ethanol alone treated HepG2/2E1 cells (You et al., 2010).

$\mathrm{Hu}$ and Kitts (2004) reported that dandelion flower extracts has also the capability to scavenge ROS and prevent DNA from ROS-induced damage in vitro. Suppression of oxidative stress by dandelion has been attributed to presence of luteolin and luteolin-7-Oglucoside. Generally, Taraxacum species are found effective against oxidative stress. Recently, it has been reported that $T$. marginellum was the most efficient extract reducing intracellular ROS levels although in vitro assays, $T$. obovatum was observed as the best free radical scavenger (Mingarro et al., 2015). Undoubtedly the above studies suggest the promising efficacy of TO against various drugs induced oxidative stress.

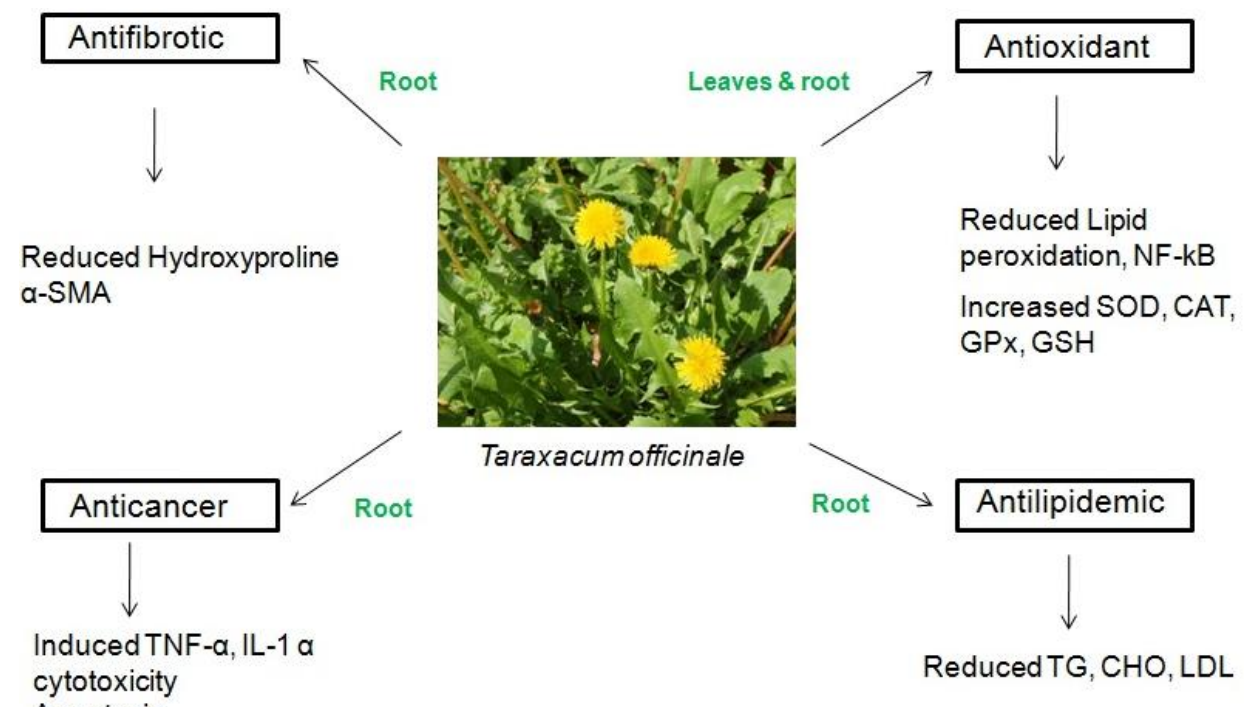

Fig. 1: Hepatoprotective effects of Taraxacum officinale. 


\section{Antifibrotic effects}

Hepatic fibrosis is common sequel following chronic liver injury and reversal of fibrosis prior it attains the cirrhotic stage would be a clear therapeutic strategy (Lee et al., 2015). TO extract has been evaluated against the drug and chemical induced hepatic fibrosis in experimental animals and came out with promising results. For instance, it has been reported that dandelion root water-ethanolic extract (DWE) ameliorated the $\mathrm{CCl}_{4}$ induced hepatic fibrosis in mice. Administration of $600 \mathrm{mg} / \mathrm{kg}$ of DWE for 10 days in mice shows significant replenishment of liver aspartate and alanine transaminases (AST and ALT) marker enzymes of hepatotoxicity, superoxide dismutase, hydroxyproline and $\alpha$ smooth muscle actin ( $\alpha$-SMA) protein expression in $\mathrm{CCl}_{4}$ induced hepatic fibrotic mice (Domitrovi'c et al., 2010). Further, this study suggests that administration TO promote the complete regression of fibrosis and the enchantment of hepatic regenerative capabilities.

\section{Antisteatotic effect}

Steatosis or alcoholic fatty liver disease has a widespread incidence and is the first step in the progression to more severe stages of alcoholic liver disease, with concomitant increases in morbidity and mortality rates (Lívero and Acco, 2015). $\mathrm{CCl}_{4}$ induced lipid changes in liver is one of the classical model for the evaluation of lipid lowering activity of drug and herbal extract. Ethanol and n-hexane leaves extract of TO significantly lower the lipid profile in $\mathrm{CCl}_{4}$ administered rats. Interestingly, $\mathrm{TO}$ significantly reduces the increase in triglyceride (TG), cholesterol (CHO), high and low density lipoproteins (HDL and LDL) (Gulfraz et al., 2014). It is reported that dandelion leaves extract has the ability to reduce the murine model of methionine- and choline-deficient diet-induced nonalcoholic steatohepatitis (NASH). In light of these studies it has been suggested that TO could also be a promising agent and has to be tested against hepatic steatosis condition (Davaatseren et al., 2013). In a recent study TO leaves extract found effective against $\mathrm{CCl}_{4}$ induced hepatic steatosis in rats. It was shown that steatosis grade was significantly reduced upon administration of TO leave extract (AlMalki et al., 2013)

\section{Anticancer activity}

Hepatocellular carcinoma (HCC) is one of the most common malignancies, which accounts for $90 \%$ of primary liver cancer. HCC usually presents with poor outcomes due to the high rates of tumor recurrence and widespread metastasis (Mao and Wang, 2015). Recent results pointed out that natural products, in particular those present in Taraxacum root extract, have great potential as non-toxic and effective alternatives to conventional modes of chemotherapy available today (Ovadje et al., 2012). Dandelion has been said to induce cytotoxicity in Hep G2 cells and decreases its viability below 40\% (You et al., 2010). TO extract significantly induced the secretion of TNF- $\alpha$ and IL-1 $\alpha$ and apoptosis of Hep G2 cells (Koo et al., 2004). These strategies are clearly implicated in anticancer efficacy of dandelion. In a very recent study it was found that relevant cytotoxic effect in $T$. lacistrum extract over HeLa and HepG2 cell lines (Mingarro et al., 2015). However, studies regarding the usefulness of TO against liver carcinoma experimental models are scanty or not available in literature. Hence, further studies are warranted in animal models to prove the promising anti-cancer efficacies of TO observed in vitro cancer cell line models i.e., Hep G2 and HeLa.

\section{CONCLUSION}

Overwhelming evidence clearly suggest that dandelion is widely used in traditional and natural medicine systems worldwide. Thus far it has received little research attention towards its beneficial effects against various hepatic ailments. In light of the studies reviewed here it has been evident that TO has the ability to intervene various pathophysiological functions related to liver. The extensive literature survey reveal the fact that Taraxacum officinalis or dandelion appear to be safe and the available evidence on the mechanisms of action appears promising, there are currently insufficient data from wellconducted clinical trials to recommend their use in patients with chronic liver diseases.

\section{REFERENCES}

Ahmed D, Gulfraz M, Ahmad MS, Tahir RM, Anwar P. Cytoprotective potential of methanolic leaves extract of Taraxacum officinale on $\mathrm{CCl}_{4}$ induced Rats. Pensee J 2013; 75:220-227.

Al-Malki AL, Abo-Golayel MK, Abo-Elnaga G, Al-Beshri H. Hepatoprotective effect of dandelion (Taraxacum officinale) against induced chronic liver cirrhosis. J Med Plants Res 2013; 7:1494-1505

Casas-Grajales S, Muriel P. Antioxidants in liver health. World J Gastrointest Pharmacol Ther 2015; 6:59-72.

Colle D, Arantes LP, Gubert P, da Luz SC, Athayde ML, Teixeira Rocha JB, Soares FA. Antioxidant properties of Taraxacum officinale leaf extract are involved in the protective effect against hepatoxicity induced by acetaminophen in mice. J Med Food 2012; 15(6):549-556.

Davaatseren M, Hur HJ, Yang HJ, Hwang JT, Park JH, Kim HJ, Kim MJ, Kwon DY, Sung M. Taraxacum official (dandelion) leaf extract alleviates high-fat diet-induced nonalcoholic fatty liver. Food Chem Toxicol 2013; 58:30-36.

Domitrović R, Jakovac H, Romić Z, Rahelić D, Tadić Z. Antifibrotic activity of Taraxacum officinale root in carbon tetrachloride-induced liver damage in mice. J Ethnopharmacol 2010; 130:569-577.

Dugum M, McCullough A. Diagnosis and Management of Alcoholic Liver Disease. J Clin Transl Hepatol 2015; 3:109-116.

Ezhilarasan D, Karthikeyan S, Vivekanandan P. Ameliorative effect of silibinin against $N$-nitrosodimethylamine-induced hepatic fibrosis in rats. Environ Toxicol Pharmacol 2012; 34:1004-1013.

Ezhilarasan D, Sokal E, Karthikeyan S, Najimi M. Plant derived antioxidants and antifibrotic drugs: Past, Present and Future. J Coast Life Med 2014; 2:738-745.

Gulfraz M, Ahamd D, Ahmad MS, Qureshi R, Mahmood RT, Jabeen N, Abbasi KS. Effect of leaf extracts of Taraxacum officinale on $\mathrm{CCl}_{4}$ induced hepatotoxicity in rats, in vivo study. Pak J Pharm Sci 2014; 27:825-829.

$\mathrm{Hu}$ C, Kitts DD. Luteolin and luteolin-7-O-glucoside from dandelion flower suppress iNOS and COX-2 in RAW264.7 cells. Mol Cell Biochem 2004; 265:107-113.

Jiang JX, Török NJ. NADPH Oxidases in Chronic Liver Diseases. Adv Hepatol 2014 Nov30; 2014. 
Koo HN, Hong SH, Song BK, Kim CH, Yoo YH, Kim HM. Taraxacum officinale induces cytotoxicity through TNF-alpha and IL1alpha secretion in Hep G2 cells. Life Sci 2004; 74:1149-1157.

Lee YA, Wallace MC, Friedman SL. Pathobiology of liver fibrosis: a translational success story. Gut 2015; 64:830-841.

Lívero FA, Acco A. Molecular basis of alcoholic fatty liver disease: From incidence to treatment. Hepatol Res 2015 Sep 29. doi: 10.1111/hepr.12594.

Mao B, Wang G. MicroRNAs involved with hepatocellular carcinoma (Review). Oncol Rep. 2015 Sep 15. doi: 10.3892/or.2015.4275.

Mingarro DM, Plaza A, Galán A, Vicente JA, Martínez MP, Acero $\mathrm{N}$. The effect of five Taraxacum species on in vitro and in vivo antioxidant and antiproliferative activity. Food Funct 2015; 6:2787-2793.

Modaresi M, Resalatpour N. The Effect of Taraxacum officinale Hydroalcoholic Extract on Blood Cells in Mice. Adv Hematol 2012; 2012:653412.

Ovadje P, Chochkeh M, Akbari-Asl P, Hamm C, Pandey S. Selective induction of apoptosis and autophagy through treatment with dandelion root extract in human pancreatic cancer cells. Pancreas 2012; 41:1039-1047.

Park CM, Youn HJ, Chang HK, Song YS. TOP1 and 2, polysaccharides from Taraxacum officinale, attenuate $\mathrm{CCl}(4)$-induced hepatic damage through the modulation of NF-kappaB and its regulatory mediators. Food Chem Toxicol 2010; 48:1255-1261.
Pereira C, Barros L, Ferreira IC. Extraction, identification, fractionation and isolation of phenolic compounds in plants with hepatoprotective effects. J Sci Food Agric 2015. doi: 10.1002/jsfa.7446.

Schütz K, Muks E, Carle R, Schieber A. Separation and quantification of inulin in selected artichoke (Cynara scolymus L.) cultivars and dandelion (Taraxacum officinale WEB. ex WIGG.) roots by high-performance anion exchange chromatography with pulsed amperometric detection. Biomed Chromatogr 2006; 20:1295-1303.

Singh A, Bhat TK, Om PS. Clinical Biochemistry of Hepatotoxicity. J Clinic Toxicol S4:001.

Vašut R., Majeský L. Taraxacum pudicum, a new apomictic microspecies of T. section Erythrosperma (Asteraceae) from Central Europe. Phytotaxa 2015; 227:243-252.

You Y, Yoo S, Yoon HG, Park J, Lee YH, Kim S, Oh KT, Lee J, Cho HY, Jun W. In vitro and in vivo hepatoprotective effects of the aqueous extract from Taraxacum officinale (dandelion) root against alcohol-induced oxidative stress. Food Chem Toxicol 2010; 48:16321637.

\section{How to cite this article:}

Ezhilarasan Devaraj. Hepatoprotective properties of Dandelion: recent update. J App Pharm Sci, 2016; 6 (04): 202-205. 